\title{
Using Robotics Competitions to Teach Teamwork Principles And Fundamental Engineering/Computer Science Concepts
}

\author{
James Giles, Anthony Richardson, Donald Roberts, David Mitchell \\ University of Evansville
}

\begin{abstract}
All freshmen in the electrical engineering, computer engineering, and computer science programs at the University of Evansville take a common "Introduction to Engineering" course during their first semester. The course is focused on exposing students to team-based, multidiscipline, and project-oriented learning. Two robotics contests are used to teach fundamental principles in electrical engineering, computer engineering and computer science. The contests have also been very effective in helping students learn to work well with one another on multidisciplinary teams. This paper describes the course format, the introductory lectures, the robot competitions, the techniques used to encourage teamwork, and assessment of the course.
\end{abstract}

\section{Introduction}

Incoming freshman in electrical engineering (EE), computer engineering $(\mathrm{CoE})$ and computer science (CS) programs take a common course during their first semester. The course is team taught by faculty members from each of the three program areas. These faculty members are the advisors to the respective students in each program area. Students are placed in teams of three or four with each team having at least one representative from each of the three programs. At the beginning of the course students are given a brief introduction to each of the programs of study. Student teams then work towards competition in two autonomous robot contests, with construction and programming of the robots taking place during the remainder of the course.

Robotics has been used for integrated educational experiences at many institutions. Carnegie Mellon University ${ }^{6,8}$ offers robot-building contests for freshman in their introduction to electrical and computer engineering course. MIT offers an undergraduate course where Lego ${ }^{\mathrm{TM}}$ building blocks ${ }^{7}$ are used as the basis for robot-building projects. For their honors fundamentals of engineering course, Ohio State incorporates a robot-building experience where students are given a budget to purchase parts that enhance their designs, with penalties for exceeding the budget and rewards for delivering a successful project at a low $\operatorname{cost}^{11}$. Several institutions have also developed robotics platforms and system boards to be used for their own courses or sold commercially ${ }^{10}$. Most courses using robotics in undergraduate education attempt to encourage motivation and excitement by making the projects competitive. In one particularly innovative course $^{9}$, the task of the robotics competition is to build a robotic toy for children with autism, which gives students additional motivation and satisfaction from helping others. 
Most of the robotics-based educational experiences are meant to motivate and excite students by giving them an interesting goal, to give students confidence for their future studies, and to introduce and illustrate a wide array of engineering topics in the context of a project. In universities, the robotics educational experiences are also intended to improve student retention. It is an evolving process to find the mix of course elements to achieve these goals. For example, there are many possibilities regarding the extent and timing for lecture-based instruction, the amount of hardware and software that should be pre-built for students, and the nature of hands on projects. Based on feedback from the courses, we make annual revisions as we better understand what works well and what needs improvement. Earlier versions of the course are described in papers by Hwang and Blandford ${ }^{1,2}$. The goal of this paper is to present the content and format of the course as it has been redesigned, and the lessons that we have learned.

The course is designed to specifically achieve several goals. By having the program advisors teach the course, students get to know and interact with their advisor on the first day of classes and throughout their first semester. It is believed that this interaction will encourage struggling students to seek assistance from their advisor earlier than they otherwise might. It is hoped that early interaction will lead to more successful students and higher retention rates. The team projects are intended to provide an early multidisciplinary team experience for students. This allows team concepts to be taught very early in the curriculum and helps to ensure that team projects in later courses have a greater chance of success. The projects also satisfy the ABET criterion for a meaningful multidisciplinary team experience.

The introduction to each of the three programs is intended to help students decide which of the three programs of study is best for them. Although our incoming students are required to declare a major, many of them are unsure about the differences between electrical engineering, computer engineering, and computer science. The introductory material aids students in selecting the program in which they are most interested. It is believed that this too helps to increase the student retention rate. The two robotics contests emphasize teamwork and application of concepts from each of the three program areas.

\section{Program Introduction}

At the beginning of the course students are given a brief introduction to each of the programs electrical engineering, computer engineering, and computer science. The sessions are taught by a faculty member from the corresponding program area, with each session taking four class periods. A brief description of the corresponding program area is presented and the program area is compared to the other two programs of study. Students are then taught fundamental concepts from the program of the study. The focus is on concepts that will help the students later in the robotics projects.

\subsection{Electrical Engineering Introduction}

In the first class period fundamental quantities such as voltage, current, resistance and power are defined. Ohm's law and the power formula are presented and students are given some simple related homework problems. Concepts such as AC and DC voltages and the requirements for a complete circuit are also defined. Schematic symbols and diagrams are also discussed. 
In the second class period students are taught to use a digital multimeter. The voltage across a single flashlight battery and then across a pair of batteries (series aiding and opposing) is measured. The current in a simple flashlight circuit is measured. The resistor color code is explained and students compare the measured resistance of an assortment of resistances to the nominal values.

At the beginning of the third period proper soldering technique is presented along with some shop safety rules. Students practice soldering components to copper-clad perf board. During the remainder of the third period and the entire fourth period the students construct a simple 9 Volt LED flasher on perf board.

Both robot projects require construction of sensor circuits. In the Electrical Engineering session, students are given enough circuit construction and troubleshooting instruction to help ensure that these circuits work properly.

\subsection{Computer Engineering Introduction}

The introduction to computer engineering material is intended to ensure that students are familiar with binary and hexadecimal number systems, basic logic operations, programming a Philips 8051-based microcontroller using Keil $\mathrm{C}^{3}$ and the WinISP ${ }^{4}$ flash programming tools, and setting and reading microcontroller port values. By covering these topics, students get a flavor for computer engineering and learn skills needed for them to complete a robot for the competitions.

In the first part of the introduction material, the binary and hexadecimal number systems are introduced. Examples are given for conversion to and from each of binary, hexadecimal, and decimal numbers. Examples of addition, subtraction, multiplication, and division in each of the systems are also given. The method for teaching this material is describing the overall technique, providing a few examples, and then giving time for the students to try example problems. Students suggest and vote on potential solutions after everyone has had an opportunity to try the example and then the instructor clarifies any misunderstandings.

After introducing the number systems, basic logic operations including "and", "or", "nand", "nor", "not", and "xor" are discussed. Truth tables are given for each of the operations and examples of logic circuits are given. A logic circuit implementing a 1-bit memory with "nor" and "not" gates is discussed. Students are given an in-class exercise in which they construct the 1-bit memory and test that it performs as expected.

Next, the Keil C programming environment is introduced through several hands-on activities. The students learn how to set up a new project and add source files to the project target. They also learn how to set the application up to produce hex code for the processor used in the Lego project. Several example code fragments are discussed and used as a basis to introduce the compiler and debugger. Students learn about basic programming constructs such as loops, delays, and function calls. Students also step through several sample programs watching the simulated port changes in the debugger. 
After the introduction to the programming environment, the students are given a circuit in which one port of the Philips 89C51RD2 microcontroller is connected to an LED. As an exercise, the students build the circuit and then program the microcontroller to flash the LED with a defined pattern. This exercise gives the students practice with Keil $\mathrm{C}$ and with the WinISP flash programmer. As an option, students are given the opportunity for further exploration by adding LEDs to the circuit and changing the flash patterns.

\subsection{Computer Science Introduction}

In this session fundamental concepts in $\mathrm{C} / \mathrm{C}++$ programming are presented. Variable types, decision structures, loops, I/O, and program documentation are discussed. Several simple programming assignments are given to reinforce the concepts. The Microsoft Visual Studio .NET development environment is used for all assignments. This is the same environment that is used in the Evolution ER1 robot project. Some time is spent during this session allowing the students to become acquainted with this development environment.

We chose to use $\mathrm{C} / \mathrm{C}++$ in this session for several reasons. Our introductory programming courses in the $\mathrm{EE}, \mathrm{CoE}$, and $\mathrm{CS}$ programs all use $\mathrm{C} / \mathrm{C}++$ as the first programming language. The Lego robots are programmed in $\mathrm{C}$ and this session is intended to provide enough background for students to write simple programs for the Lego robots. The ER1 robots can be programmed in almost any computer language. We chose to use $\mathrm{C}++$ because of the similarity between $\mathrm{C}$ and $\mathrm{C}++$. The $\mathrm{C}++$ development environment that is used to program the ER1 robots is very similar to the development environment that is used to program the Lego robots.

\section{Robotics Contests}

The robotics contests seem to be ideal projects for this course. They are difficult enough to require a true team effort to complete and yet not to difficulty for students with little or no experience in engineering and computer science. They also help to reinforce the fundamental concepts taught in the program introduction sessions.

Two large groups are formed from the student teams. One group works with the Lego robots while the other group works with the ER1 robots. The groups work with their respective robots for about 12 class periods. Two class periods are then used to hold the robot competitions.

Each team is required to keep a design notebook. In addition to schematic diagrams and program listings the design notebooks are used to document day-to-day activities of the team. The design notebooks and the performance of the robots in the contests are the main factors in determining grades at the end of the term.

\subsection{Lego Robot Contest}

The goal of the Lego robot contest is to provide an opportunity for students to apply knowledge they have gained as part of the discipline introductions and to encourage students to engage in collaborative design. Students construct a robot using Lego ${ }^{\text {TM }}$ building blocks, two bump switches, two motors, an "eye board", and a processor board which includes a Philips 
89C51RD2 microcontroller along with several input and output ports and an $\mathrm{A} / \mathrm{D}$ converter. Using a supplied library of functions, the students construct a program that enables the robot to autonomously compete in the contest. The contest itself is a secondary consideration meant to provide motivation for the design activities.

To compete in the contest, the Lego ${ }^{\mathrm{TM}}$ robots from all of the teams concurrently move around an arena looking for any of nine "beacons". A beacon, shown in Figure 1, emits a modulated infrared signal with different frequencies indicating different types of beacons. The beacon types include a 10 point beacon type, a 20 point beacon type, and a "bomb" beacon type. A beacon randomly changes types several times during a round, including any time that a robot comes into contact with it. In a given round, the goal is to collect points by coming into contact with 10 or 20 point beacons, without going near "bomb" beacons. When a robot has come into contact with a bomb beacon, it "explodes" by activating a party popper and no longer changes to another beacon type. If a robot is within 3 feet of a beacon when it explodes, regardless of whether that robot contacted the beacon, then the robot is considered "blown up" and out of the competition unless the team buys back into the competition by incurring 50 penalty points. To keep robots from scoring continually with the same beacon, after a beacon has been contacted three times while in 10 or 20 point mode, the beacon is a "bomb" type beacon for the remainder of the contest. The contest consists of two rounds lasting up to 10 minutes (or as soon as all of the beacons have "exploded"), with points from the two rounds summed to determine the winner.

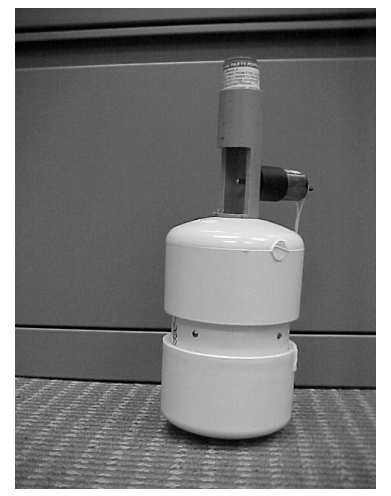

Figure 1: Beacon

The hardware provided to the students includes a main processing board, motors, bump switches, and an "eye board". The schematic for the main processing board is illustrated in Figure 2. Besides the Philips microprocessor, the main processing board includes a Philips 74HC373 transparent latch for buffering input from the bump switches, a Texas Instrument SN754410 Half-H driver for driving the motors, a National Semiconductor ADC0848 8-bit analog to digital to read the infrared signal strength reported by the "eye board", a buzzer for diagnostics, and an unused Philips 74HC374 D-type flip flop for digital output. The main processor board can be connected to a personal computer for programming and diagnostic purposes using a built-in RS232 port. The eye board illustrated in Figure 3 consists of two infrared detectors connected to a tunable amplification and filtering circuit for obtaining the beacon signal strength and a clipping circuit that assists the microprocessor in determining the beacon type. 


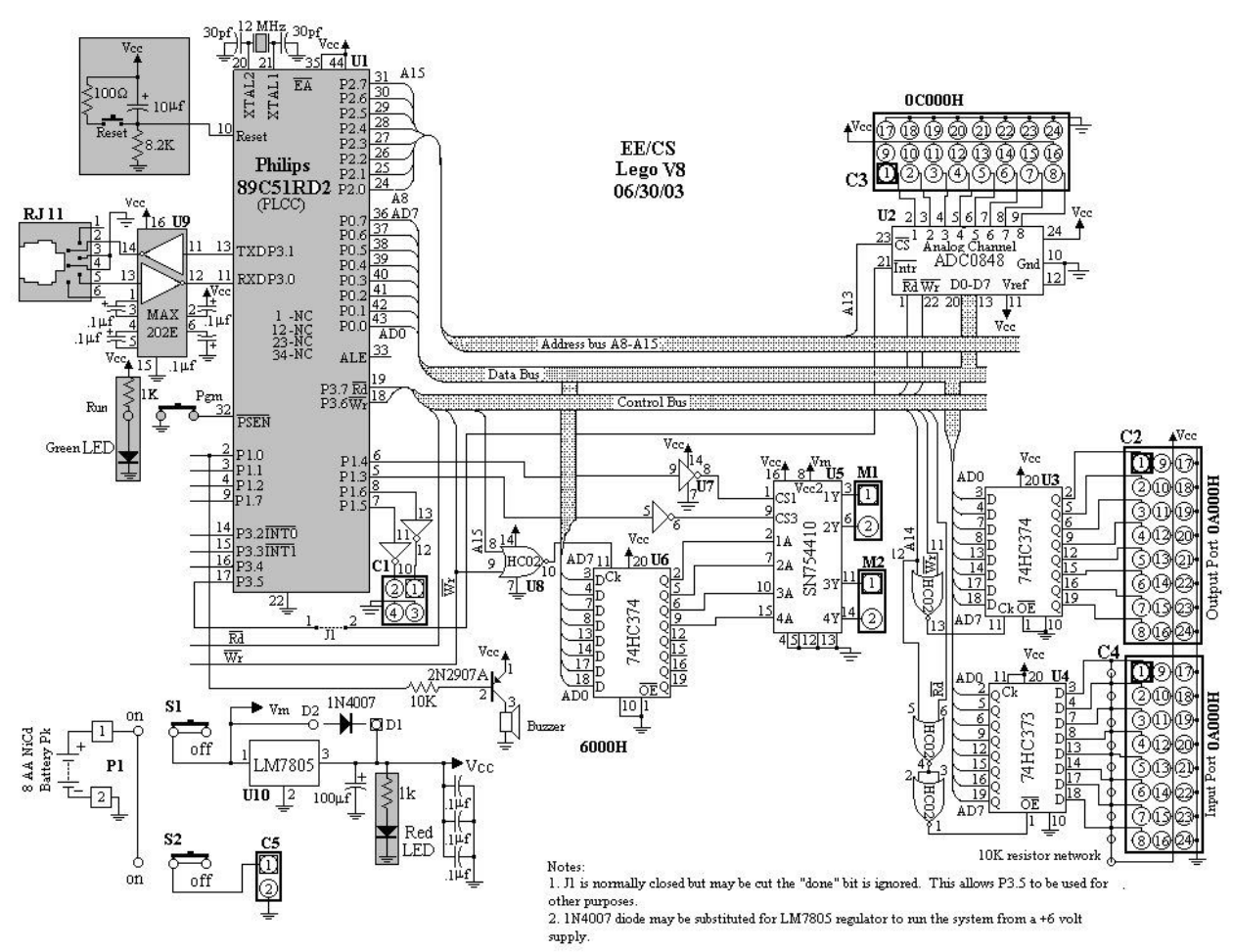

Figure 2: Controller board schematic

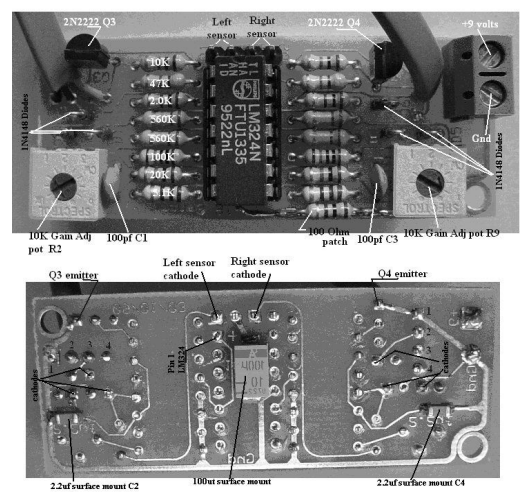

Figure 3: Eye Board

Students construct a mechanical robot according to their own design with the Lego ${ }^{\text {TM }}$ building blocks and then in stages assemble the additional hardware by connecting battery packs, motors, bump switches, and the "eye board" to the processor board. In the first assignment, students are asked to program the vehicle so that it will just move in a square pattern, spin the vehicle, and then stop. This gives them the opportunity to experiment with programming the car and controlling the motors. In the second assignment, students are asked to program the vehicle so that it moves forward until contacting something with the bump switches and then it should back up, turn 90 degrees in the direction away from the bump switch that is contacted, and then repeat the process. This gives the students an opportunity to build on what they have learned with the motors and to start incorporating the bump switches. In the third assignment, students are asked to write a program to track and contact a beacon. In addition, their program should cause the 
vehicle to indicate the beacon type by beeping 1,2, or 3 times depending on whether a 10-point, 20-point, or "bomb" beacon is being tracked. After contacting the beacon, the students are asked to turn away from it and to try to track another beacon. To aid in troubleshooting hardware problems, a diagnostic program provided to the students can be used to determine the signal strength being read by the eye board, the beacon type of the currently visible beacon, and the status of the bump switches. The diagnostic tool reports these values to a personal computer terminal emulation program using the RS-232 port. Having multiple assignments encourages the good practice of getting one component system functioning with the overall system before adding the next.

To aid in the programming tasks, a library of routines that simplify the interface are provided to the students. The functions provided by the library are described in Table 1. Students are given the source code for the functions to aid in learning and to allow them to modify or enhance the functions as needed.

\begin{tabular}{|c|c|}
\hline $\begin{array}{l}\text { unsigned char } \\
\text { BeaconType (); }\end{array}$ & $\begin{array}{l}\text { Returns } 0,1,2 \text {, or } 3 \text { depending on whether the beacon type cannot be } \\
\text { identified, it is a } 10 \text { point beacon, it is a } 20 \text { point beacon, or it is a } \\
\text { "bomb" beacon respectively. }\end{array}$ \\
\hline $\begin{array}{l}\text { Delay(unsigned char } \\
\text { count); }\end{array}$ & Delays count*100ms (blocking) \\
\hline $\begin{array}{l}\text { SetMotor(unsigned char } \\
\text { motorID, int speed); }\end{array}$ & $\begin{array}{l}\text { Sets motor with motorID } 1 \text { or } 2 \text { to speed }-255 \text { to } 255 \text { where a speed of } \\
0 \text { stops a motor, a speed of } 255 \text { turns the motor in one direction full } \\
\text { speed, and a speed of }-255 \text { turns the motor in the opposite direction } \\
\text { full speed. }\end{array}$ \\
\hline AllStop(void); & Stops both motors \\
\hline $\begin{array}{l}\text { unsigned char } \\
\text { ReadInputPort (unsigned } \\
\text { char num); }\end{array}$ & $\begin{array}{l}\text { Returns } 1 \text { when input port num closed, } 0 \text { when input port num open, } \\
\text { where num is indexed from } 0 \text { to } 7 \text {. Used for reading bump switches. }\end{array}$ \\
\hline $\begin{array}{l}\text { Beep(unsigned char } \\
\text { duration); }\end{array}$ & Oscillates buzzer for duration cycles. \\
\hline $\begin{array}{l}\text { unsigned char GetAtoD } \\
\text { (unsigned char channel); }\end{array}$ & $\begin{array}{l}\text { Returns the value from } 0 \text { to } 255 \text { read from the given A to D channel } \\
\text { indexed } 0 \text { to } 7 . \text { Used to read the signal strength from a beacon. }\end{array}$ \\
\hline Initialize(); & Set up all of the library routines and sets the motors to all stop. \\
\hline
\end{tabular}

Table 1: Library routines

When the Lego robot design process has completed, the robots participate in the contest. A typical robot is illustrated in Figure 4. In general, many of the robots are able to achieve a positive score during the competition, but there are usually one or two teams who have a lastminute hardware or software problem that keeps their robot from moving. Nevertheless, students enjoy the competition and it is a significant motivator for them to stretch their abilities with unfamiliar tools, components, and methods. 


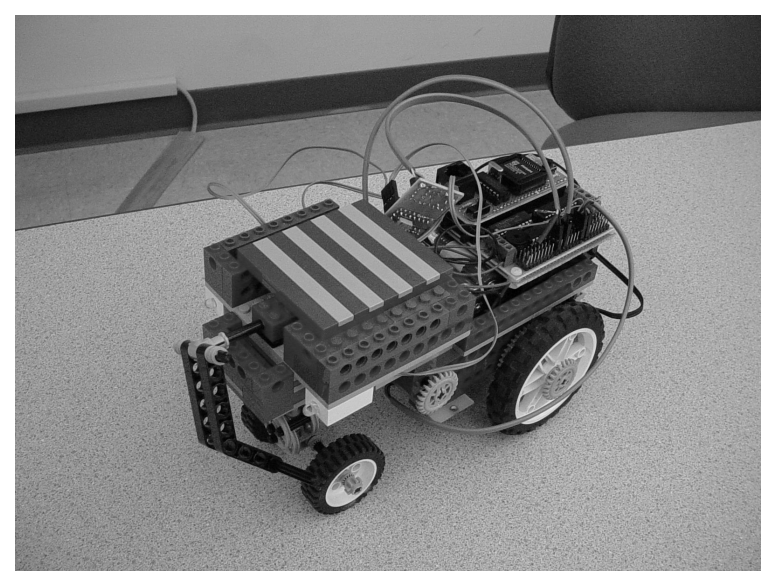

Figure 4: Lego robot

\subsection{Evolution ER1 Robot Contest}

The ER1 robot from Evolution Robotics ${ }^{5}$ is a excellent platform for introductory robotics projects. The basic platform is available for under $\$ 300$. (An additional laptop computer is required to control the robot however.) The ER1 is shown in Figure 5. A microcontroller is used to operate the two stepper motors. An eight bit digital I/O port and sixteen analog input ports are available. These ports allow a number of additional sensors to be connected to the robot for a variety of projects. The microcontroller is not directly programmable. A laptop computer, which is connected to the microcontroller by a USB cable, is used to program the robot.

Video input is through a USB camera connected to the laptop. Audio input/output are available through a microphone and speakers on the laptop. The ER1 comes with software known as the Robot Control Center (RCC). The RCC provides image and sound recognition capability. It also provides a graphical programming environment in which to program fairly complex behaviors. More sophisticated control is available through the Application Programming Interface (API) to the RCC. The API must be used to access the digital and analog ports. The interface is through a TCP/IP port and so can be programmed directly on the laptop or by another computer on the network. With wireless networking cards in the laptops we find it most convenient to interface with the RCC software from another computer on the network.
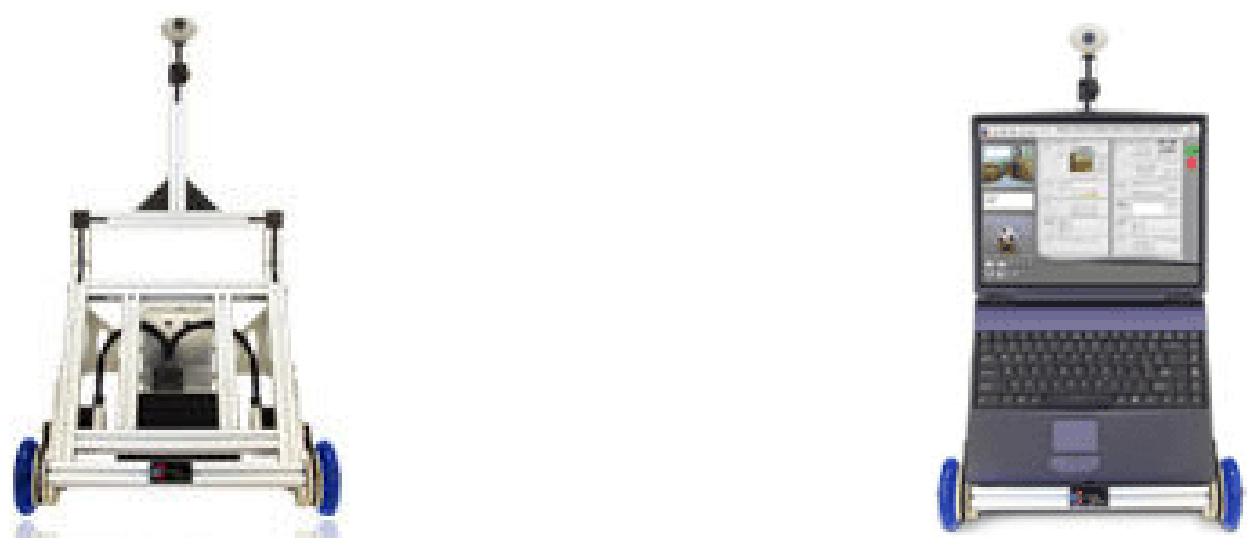

Figure 5: ER1 Robot (Shown at right with the required laptop computer) 
The API is text based. The text based interface means that the robot control program can be written in almost any modern language. We use $\mathrm{C}++$ in our introductory programming course and so choose to use that language for this project. Because the string processing that is required to effectively use the text based API directly can be tricky to master for beginning programmers, a robot class library that hides the details of the underlying API is provided to the students. The class library also introduces the students to object-oriented programming. With the class library a simple robot control program would look like this:

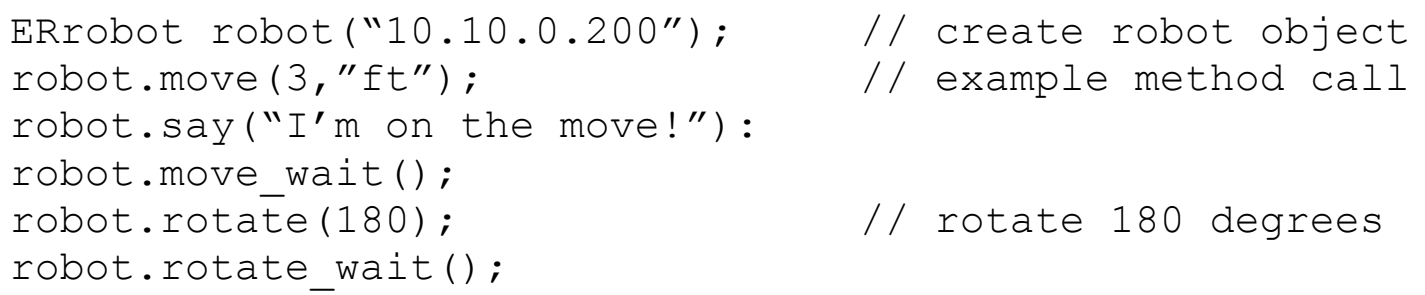

The wait() methods in the program ensure that the particular motion completes before the program continues. The robot does not queue motion commands. Additional motion commands cause previous ones to be aborted. This is usually desirable behavior. You can monitor the input, video, or audio input ports and then immediately change the robot motion in response to input.

The class library makes all of the features of the API available to the $\mathrm{C}++$ programmer. Fairly complex behaviors can be implemented with small programs. Writing programs for the ER1 robots is both satisfying and exciting to beginning programmers. The robots provide visual verification of program correctness. Programming concepts like decision and loop structures are strongly reinforced when they directly translate to robot motions.

Although fairly sophisticated programs can be written using the available image and sound recognition capabilities of the software, we wanted to have each team build a simple sensor board that would make use of the digital and analog I/O ports on the robot. This also introduces a few electrical engineering topics into the project.

In the contest the robots had to follow a zigzagging line laid down in the lobby of the engineering building. The line was approximately thirty feet long and roughly in the shape of the letter "U". The winner would be the robot that completed the course in the fastest time. If no one completed the course in five minutes the winner would be the robot that went the farthest on the course.

For the robot to follow the line, each team had to build an infrared transceiver board that was connected to the digital and analog I/O ports on the robot. A schematic of the board is shown in Figure 4. At the top of the schematic are three LEDs and two IR transmitters. One of the LEDs is a power indicator that lights when the board is properly connected to the I/O port on the robot. The other two LEDS and both IR transmitters can be turned on and off by writing the appropriate byte to the digital output port. At the bottom of the schematic are two IR receivers. These are connected to two of the robot's analog input ports. Voltages between 0 and $5 \mathrm{~V}$ at the analog port are converted by an $\mathrm{A} / \mathrm{D}$ converter to digital values between 0 and 32768 . These values 
indicate the IR intensity at the IR receiver. The entire circuit is built on a 1" $\mathrm{x} 3$ " custom PCB. By writing the proper byte to the digital I/O port the IR transmitters are turned on. Values are read from the two analog ports to determine the IR intensity at each of the two receivers ("eyes"). By monitoring the values from the eyes students can determine whether the robot has moved to either the left or the right of the line.

While one member of the team is building the IR transceiver board, the other members work on several simple robot programming exercises. The team member that constructs the board assumes the role of the circuit designer in this project. The circuit designer has the responsibility of explaining the operation of the circuit to the rest of the team. In particular, the circuit designer must explain the particular values written to the digital port turn the transmitters on and off. The designer must also explain the software interface to the analog input ports.

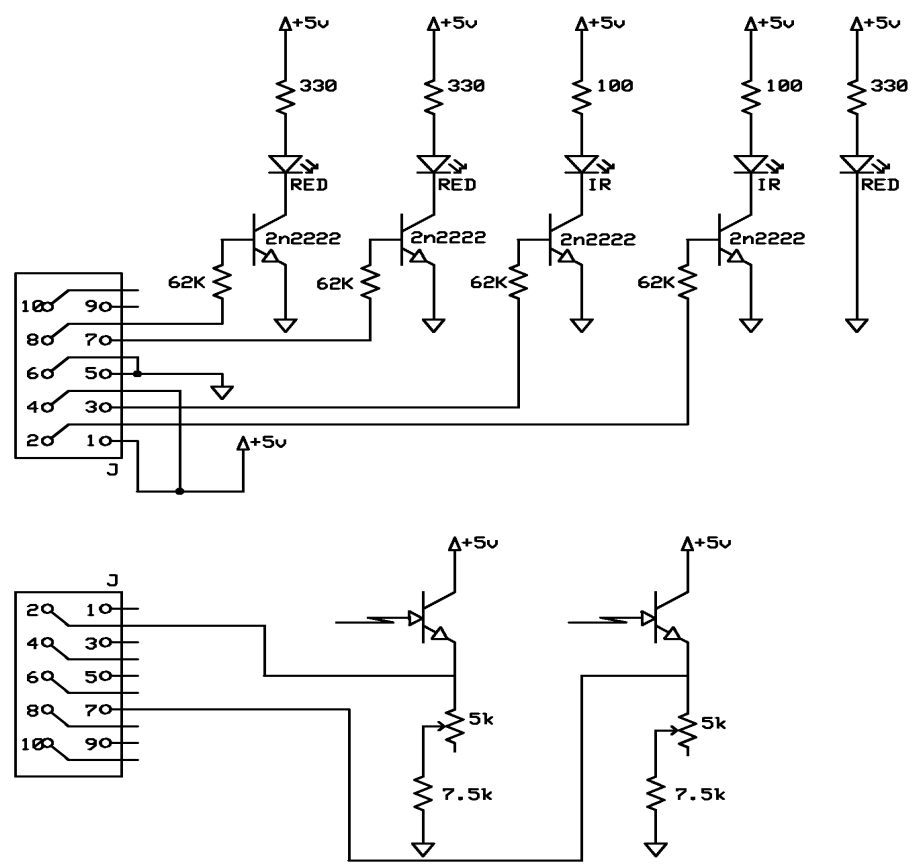

Figure 4: IR Transceiver Board for ER1 Robot

\section{Assessment}

Anecdotal faculty observations of the class suggest that many of the course goals were met. Because students worked on the projects throughout the semester as groups of three or four, many formed friendships and working relationships that have been observed to extend beyond the course. It is believed that these friendships will give students a support structure and help with student retention. The desire to support teammates and interest in the projects resulted in very good attendance from most students. Many of the teams were able to complete innovative and functional designs, while most students seemed to have grasped the concepts even if their designs were not as competitive. For the most part, student notebooks documenting the course and the design process were complete and insightful. The faculty also observed students taking the lead in aspects of design related to their chosen discipline. However, a weakness identified during the formal assessment of the course is that the projects need to be rebalanced to include more electrical engineering and computer engineering components and a little less programming. 
The course was formally evaluated by the students and overall received some of the highest ratings of courses offered by the department. Students generally responded favorably in comments about the course, but some also identified weaknesses such as the project bias towards programming. Many students thought the teamwork was a very important part of the class. One student wrote, "You gain a perspective on many ideas when you work in a group" and another wrote, "The teamwork was very useful in this class". When summarizing the course, one student wrote, "I feel this course is a great introduction to this field of study." A second student wrote, "I have had a wonderful time in this class; it is the one class I have where 50 minutes seems more like 10 minutes due to all of the stuff we are constantly doing." A third student commented, "The course is by the most interesting and challenging in my freshman year...the course encourages team work and critical thinking." Indicating the inspiration the course provided, another student said, "I can't wait for next semester."

\section{Summary}

Based on student interviews and course evaluations this course has successfully met its goals. After completing the course the students have a much clearer understanding of the type of work performed by electrical engineers, computer engineers, and computer scientists. The robot contests have helped to excite the students about their choice of major and the faculty members involved believe that this will help to increase the student retention rate.

The robot contests have been very effective in allowing students to participate in a multidisciplinary team experience. The introductory sessions help to prepare and motivate students for subsequent courses.

\section{Acknowledgements}

The authors wish to express their gratitude to Mark Randall. Mark's assistance is all aspects of this course have helped to make it successful.

\section{Bibliography}

1. D. Hwang, D. Blandford, “A Multidisciplinary Team Project for Electrical Engineering, Computer Engineering, and Computer Science Majors”, Proceedings of ASEE 2000 Annual Conference, St. Louis, MO, June 18-21,2000

2. D. Blandford, D. Hwang, A. Richardson, "LEGO 101: A Multidisciplinary Freshman Team Experience", Proceedings of the ASEE 2001 Annual Conference, Albuquerque, NM, June 24-27, 2001

3. Keil Software, 8051 Development Tools, http://www.keil.com/c51/.

4. Philips, WinISP Flash Utility, http:/www.semiconductors.philips.com/ markets/ mms/ products/ microcontrollers/support/software_download/ 8051/ index.html.

5. Evolution Robotics Inc, ER1 Wē Site http://www.evolution.com/er1/

6. J. Tomayko, “Carnegie Mellon's Software Development Studio: A Five Year Retrospective”, Proceedings of $9^{\text {th }}$ Conference on Software Engineering Education, Daytona, FL, 1996.

7. F. Martin, P. Oberoi, R. Sargent, “The 6.270 Robot Builder's Guide”, MIT Media Lab, Cambridge, MA, 1992.

8. Carnegie Mellon University, "Introduction to Electrical Engineering Student Robotics Project", http://www.cit.cmu.edu/ugweb/e_stuproj_robots.html. 
9. F. Michaud, M. Luca, G. Lachiver, A. Clavet, J.-M. Dirand, N. Boutin, P. Mabilleau, J. Descoteaux, "Using ROBUS in Electrical and Computer Engineering education", Proceedings of the American Society for Engineering Education, Charlotte, June, 1999.

10. HandyBoard.com, "MIT Handy Board", http://handyboard.com.

11. R. J. Freuler, M. J. Hoffman, T. P. Pavlic, J. M. Beams, J. P. Radigan, P. K. Dutta, J. T. Demel, E. D. Justen, "Experiences with a Comprehensive Freshman Hands-On Course - Designing, Building, and Testing Small Autonomous Robots", Proceedings of ASEE 2003 Annual Conference, Nashville, TN, June 20-23, 2003.

JAMES GILES is an Assistant Professor at the University of Evansville. He received a $\mathrm{PhD}$ in Electrical Engineering from the University of Illinois.

ANTHONY RICHARDSON is an Assistant Professor at the University of Evansville. He received a $\mathrm{PhD}$ in Electrical Engineering from Duke University.

DONALD ROBERTS is an Assistant Professor at the University of Evansville. He received a $\mathrm{PhD}$ in Computer Science from the University of Illinois.

DAVID MITCHELL is an Associate Professor at the University of Evansville. He received a MS in Electrical Engineering from the University of Toledo. 